Biochem. Lett., Vol. 7, PP. 65-89 (2012)

\title{
THERAPEUTIC EFFECTS OF CURCUMIN ALONE AND IN COMBINATION WITH DOXORUBICIN AGAINST IN VIVO INDUCED BREAST CANCER
}

\author{
Faten Zahran ${ }^{1}$, Ahmad Raafat ${ }^{(2)}$, Afaf I. El-attar ${ }^{1}$ \\ ${ }^{1}$ Biochemistry Division, Dept. of Chemistry, Faculty of \\ Science, Zagazig University; ${ }^{2}$ Faculty of Science, \\ Biochemistry Division \\ , Alexandrina University.
}

\begin{abstract}
ABSRACT
Drug resistance during tumor progression is a true problem as this is the major reason for the failure of breast cancer therapy. High constitutive activation of nuclear factor kappa $B$ ( NF-kB) has been found in different cancers, creating an environment conducive for chemotherapeutic resistance. Curcumin, one of the most studied chemo preventive agents, is a natural compound extracted from Curcuma longa $L$. that allows suppression, retardation or inversion of carcinogenesis. Doxorubicin (DOX) is a drug that is widely used for the treatment of a variety of cancers including breast and liver cancers. This study aims to investigate the effect of combination of curcumin with doxorubicin in breast cancer treatment and provide a new suitable method to overcome cancer resistance. Results: We found that administration of curcumin $(200 \mathrm{mg} / \mathrm{kg}$ b.w.) with doxorubicin $(1.25 \mathrm{mg} / \mathrm{kg} \mathrm{b.w.)}$ results in disappearance of tumor cells $(E A C)$ and results in highly significance decrease of NF-kB. An antioxidant effect of curcumin in vivo was observed; our results investigate a significant increase in antioxidant enzymes.. Conclusion: Curcumin has a strong inhibitory activity against tumors. The combination of curcumin with doxorubicin resulted in a synergistic antitumor activity. These results suggest that curcumin can be developed into an adjuvant chemotherapeutic drug to overcome drug resistance of cancer.
\end{abstract}




\section{Therapeutic Effects Of Curcumin}

\section{INTRODUCTION}

Cancer is clearly a worldwide problem. The incidence and mortality rates for various cancers are similar, though not identical, among developed countries. Cancer is a leading cause of death ${ }^{(1)}$. Recent reports suggest that globally, in the year 2008, 12.7 million new cancer cases and 7.6 million cancer deaths occurred ${ }^{(2)}$. The etiology of breast cancer is multi-factorial. Hormonal, genetic, and environmental factors appear to interplay in the pathogenesis of breast cancer ${ }^{(3)}$. Breast cancer is caused by the uncontrolled proliferation of breast cells which is happened because of their ability to avoid apoptotic mechanism ${ }^{(4)}$. Though chemotherapy plays an important role in the treatment of breast cancer, the high-percentage of non-responders and of failures following initial responses highlights the critical role played by drug resistance mechanisms in breast cancer management ${ }^{(5)}$. Mechanistically, the resistance phenomena may be explained by (i) mutation or over-expression of drug target proteins, and/or (ii) inactivation of drugs by a reduction in uptake or enhanced detoxification and removal of drugs ${ }^{(6)}$. It is, therefore, essential that new therapeutic options are needed for cancer therapy with attention to toxicity and side effects, besides the major treatment modalities including surgery, immunotherapy and radiotherapy

${ }^{(7,8)}$. Experimental tumors have great importance for the purposes of modeling, and Ehrlich ascites carcinoma (EAC) is one of the commonest. It appeared firstly as a spontaneous breast cancer in a female mouse, EAC is referred to as an undifferentiated carcinoma and is originally hyper diploid, has high transplantable capability, no-regression, rapid proliferation, shorter life span, $100 \%$ malignancy and also does not have tumor-specific transplantation antigen (TSTA). Frequently, tumor virulence increases via repetitious passages, while the proliferating rate of such tumors increases gradually $^{(\boldsymbol{9})}$. However, the differentiation gradually disappears, while the cells get free growth control mechanisms, gain hetero-transplant ability and in the end, they are converted to the ascites' form. EAC resembles human tumors which are the most sensitive to chemotherapy due to the fact that they are undifferentiated and that they have a rapid growth rate ${ }^{(\mathbf{1 0})}$. Carcinogenesis is a formation proceeding through at least three different stages including initiation, promotion, and progression, ROS can stimulate carcinogenesis by acting at all three stages. ${ }^{(11)}$.Oxidative stress is defined as an imbalance between production of Free radicals and reactive metabolites, so-called oxidants or reactive Oxygen species (ROS), and their elimination by protective mechanisms, referred to as antioxidants. This imbalance leads 
Faten Zahran. et al.

to damage of important bio-molecules and cells, with potential impact on the whole organism ${ }^{(12)}$. Curcumin (1,7-bis(4-hydroxy 3-methoxy phenyl)-1,6heptadiene-3,5-dione) is a phenolic compound extracted from the rhizome of Curcuma longa L. (family Zingiberacae) and it is commonly used in the Asian continent, especially in India, as a spice to make food colored and flavored. Furthermore, traditional Indian medicine has considered curcumin a drug effective on several disorders including anorexia, coryza, cough, hepatic diseases, and sinusitis ${ }^{\mathbf{1 3})}$. In both in vitro and animal studies, curcumin has shown antitumor ${ }^{(14)}$,antioxidant, antiarthritic, antiamyloid, anti-ischemic and anti-inflammatory properties ${ }^{(15)}$ Doxorubicin, an anthracycline antibiotic, is one of the commonly prescribed chemotherapeutic agents against a wide-spectrum of cancers including breast cancer $^{(16)}$.However, the clinical efficacy and usefulness of doxorubicin-based treatment regimens is still limited because of dose-limiting toxicity and induction of drug resistance ${ }^{(17) .}$ Resistance to the apoptotic effect of doxorubicin is speculated to be multi-factorial, involving the activation of nuclear factor $\mathrm{kB}$ in cancer cells ${ }^{(\mathbf{1 8})}$. NF_ $\mathrm{kB}$ a transcription factor protein complex, is found in nearly all animal cell types ${ }^{(19)}$.It regulates the expression of a host genes involved in inflammation, cellular proliferation and cell survival ${ }^{(20)}$. Incorrect regulation of $\mathrm{NF}_{-} \mathrm{\kappa B}$ has been linked to inflammatory and autoimmune diseases, septic shock, viral infection and improper immune development ${ }^{(21)}$.

\section{MATERIALS \& METHODS}

Animals: Seventy Adult Female Swiss albino mice of 8 weeks of age, weighed 20 to $25 \mathrm{~g}$ body weight were used in this study, and were purchased from breeding unit of the Egyptian Stock Holding Company for Biological Products of Vaccines. the animals were raised at the experimental animal house of the faculty of Science, Zagazig University. The animals were maintained in controlled environment of temperature, humidity and light. They were fed on a commercial standard diet and adlibitum water.

Tumors Ehrlich ascites carcinoma (EAC) was initially supplied by the National Cancer Institute, Cairo, Egypt, and maintained in female Swiss albino mice through serial intraperitoneal (I.P) inoculation at 8 or 10 day intervals in our laboratory in an ascites form. 


\section{Therapeutic Effects Of Curcumin}

Curcumin : Curcuminoids C3 complex capsules (95\%) were purchased from America's Finest, Inc. (USA). Bioperine was added to curcumin in order to increase its bioavailability. Curcumin powder $(400 \mathrm{mg} / \mathrm{Kg})$ was dissolved in saline.

Bioperine: is a standardized extract from the fruits of Piper nigrum L. (black pepper) or Piper longum L. (long pepper). It contains a minimum piperine content of $95 \%$ compared to the $3-9 \%$ and $3-5 \%$ found in raw forms of Piper nigrum and Piper longum, respectively. BioPerine was found to enhance absorption of curcumin.

Doxorubicin: It also known as (hydroxy daunorubicin) is a drug used in cancer chemotherapy. It is an anthracycline antibiotic, closely related to the natural product daunomycin, and like all anthracyclines, it works by intercalating DNA. Dox.Was purchased from pharmacy. This drug (2.5 $\mathrm{mg} / \mathrm{Kg}$ b.w.) was dissolved in saline.

Experimental design:To determine the combinatorial therapeutic efficacy of curcumin and doxorubicin, $2.5 \times 10^{6}$ (EAC) cells were intraperitonially injected in mice and cancer cells were allowed to grow up to 7 days. Then the mice were divided in to seven groups (10 mice in each group) and treated as follows: Group 1, received a saline solution by I.P. injection represented as negative control(C-) group, Group 2, received EAC cells $\left(2.5 \times 10^{6}\right.$ cells/mouse $)$ by I.P. injection for 10 days served as positive control $(\mathrm{C}+)$ group. Group 3,injected I.P. with EAC $\left(2.5 \times 10^{6}\right.$ cells $/$ mouse $)$, then after 7 days, mice were injected IP with Doxorubicin $(2.5 \mathrm{mg} / \mathrm{Kg}$ b.w.) once a week for 3 weeks, represented as Doxorubicin (C+\&Dox.) group, Group 4, injected I.P. with EAC $\left(2.5 \times 10^{6}\right.$ cells/mouse), then after 7 days,mice were orally treated with curcumin $(400 \mathrm{mg} / \mathrm{Kg} \mathrm{b.w}$.) day after day up to 21 days., represented as therapeutic $(\mathrm{C}+\& \mathrm{Cur}$.)group, Group 5, orally treated with Curcumin $(400 \mathrm{mg} / \mathrm{Kg}$ b.w.) twice weekly for 2 weeks before EAC inoculations, then after 7 days of EAC inoculations, Followed by orally treatment with Curcumin day after day up to 21 days, represented as preventive (Cont-Cur.)group, Group 6,injected I.P. with EAC $\left(2.5 \times 10^{6}\right.$ cells/mouse), then after 7 days, followed by IP injection of Doxorubicin $(1.25 \mathrm{mg} / \mathrm{Kg}$ b.w.), then after 7 days ,mice orally treated with curcumin $(200 \mathrm{mg} / \mathrm{Kg}$ b.w.) day after day up to 21 days, represented as Combination Therapeutic $(\mathrm{C}+\& \mathrm{Dox}+\mathrm{Cur}$.) group. Group7, treated orally with Curcumin (200mg/Kg b.w.) twice weekly for 2 weeks before EAC 
inoculations, then after 7 days of EAC inoculations, followed by IP injection of Doxorubicin $(1.25 \mathrm{mg} / \mathrm{Kg} \mathrm{b}$.w.), then after 7 days, mice orally treated with curcumin $(200 \mathrm{mg} / \mathrm{Kg} \mathrm{b.w}$.) day after day up to 21 days, represented as Preventive-combined therapy (Cont-Dox\&Cur.) group. Mice of seven groups were maintained under the same conditions and were carefully observed to the end of experiment. After the experiment, blood samples, liver tissue and EAC cells were collected from mice for determination of antioxidant enzymes assays, liver enzymes assays, kidney function tests, NF$\mathrm{kB}$ assay, cytological study and histopathological studies.

\section{Cell Viability and Counting of EAC cells:}

the viability of EAC cells was determined by the Trypan Blue Exclusion Method ${ }^{(22)}$. where the total and viable cells (non-stained) were counted in thomacytometer at magnification $\times 40$; as the number of cells $/ \mathrm{ml}$ was determined in the studied groups.

\section{Antioxidant Enzymes Assays:}

I) Estimation of Superoxide Dismutase (SOD) in liver: it was determined according to the method of Nishikimi et $\mathrm{al}^{(23) \text {. }}$

II) Estimation of catalase activity in liver: Determination of liver catalase activity was assayed according to the method of Aebi ${ }^{(24)}$.

III)Estimation of Glutathione Peroxidase (GPx) activity in liver: it was determined by according to the method of Paglia and Valentine ${ }^{(25) .}$

\section{Liver Enzymes Assays:}

Determination of Transaminases: Serum samples were screened for liver function enzymes are Alanine Transferase (ALT) and Aspartate Transferase (AST). both enzymes are determined according to the method of Reitman and Frankel $^{(26)}$.

\section{Kidney Function Assays:}

I)Determination of serum Creatinine :- it was determined according to the method of Bartles et al ${ }^{(27)}$.

II) Determination of serum Urea:-it was determined according to the method of Fawcett and Soctt ${ }^{(28)}$.

Estimation of NF-kB in Nuclear Extract: Nuclear factor-kB p50/65 DNAbinding activity in nuclear extracts of hepatic tissue samples was evaluated 


\section{Therapeutic Effects Of Curcumin}

to measure the degree of NF-kB activation. Analysis was performed according to the method of Adams ${ }^{(29) .}$

Cytological Study of EAC cells: It was determined according to the method of Amer. ${ }^{(30)}$.

Histopathological Studies: It was determined according to the method of Culling ${ }^{(31)}$.

Statistical Analysis: All results were analyzed by SPSS software (version $14)^{(32)}$. Data were expressed as mean \pm SD. The student's $t$ test was used for statistical analysis of differences between each two groups. Comparison of mean values of studied variables among different groups was done using ANOVA test. $\mathrm{P}<0.01$ was considered to be significant.

\section{RESULTS}

\section{Effect of Doxorubicin and Curcumin on the viability and counting of EAC cells:}

Table (1) summarizes the effect of Doxorubicin as chemotherapeutic drug and curcumin as chemo-preventive natural product; where Doxorubicin administration results in a very highly significant reduction of EAC growth in vivo; indicating decrease in the volume of EAC by $73.2 \%$ in $C+\& D o x$. Group compared to positive control group as shown in Fig. (1a); and a significant decrease in the count of EAC by $90.67 \%$ in C $+\&$ Dox. Group compared to positive control group as shown in Fig. (1b)., while Curcumin administration results in a very highly significant decrease in the volume of EAC by $61.5 \%$ and $70.94 \%$ in the therapeutic and preventive groups, respectively; compared to positive control group; as shown in Fig. (1a); and a very highly significant decrease in the count of EAC by $76.42 \%$ and $86.43 \%$ in the therapeutic and preventive groups, respectively; compared to positive control $(\mathrm{p}<0.001)$; as shown in Fig. (1b).

While in both group 6 (Combination Therapeutic $(\mathrm{C}+\& \mathrm{Dox}+\mathrm{Cur}$ ) and group 7(Preventive-combined therapy (Cont-Dox\&Cur.), the administration of doxorubicin with curcumin results in completely disappearance of EAC cells thus mice in these two groups are recovered from tumor with this combined treatment. 
Faten Zahran. et al.

Table (1): Effect of Curcumin on the volume and count of EAC in the studied groups:

\begin{tabular}{|l|l|l|l|l|}
\hline Parameter & Group 2 & Group 3 & Group 4 & Group 5 \\
\hline $\begin{array}{l}\text { Volume of } \\
\text { Ascitis } \\
\text { Fluid (ml) }\end{array}$ & $7.95 * * * \pm 0.72$ & $2.13 * * * \pm 0.24$ & $3.06 * * * \pm 0.46$ & $\begin{array}{l}2.31 * * * \pm \\
0.49\end{array}$ \\
\hline $\begin{array}{l}\text { Count of } \\
\text { EAC cells ( } \\
\left.\times \mathbf{1 0}^{6}\right)\end{array}$ & $141.54 * * * \pm 9.3$ & $13.2 * * * \pm 1.84$ & $33.37 * * * \pm 3.95$ & $\begin{array}{l}19.2 * * * \pm \\
3.24\end{array}$ \\
\hline
\end{tabular}

- Numerical data were expressed as mean \pm SD. Preventive and therapeutic groups were compared to positive control group.

- $\quad * \mathrm{P}$ value $<0.05$ was considered significant. ** $\mathrm{P}$ value $<0.01$ was considered highly significant.

- $\quad * * * \mathrm{P}$ value $<0.001$ was considered very highly significant. N.S. P value $>0.05$ was considered non significant.

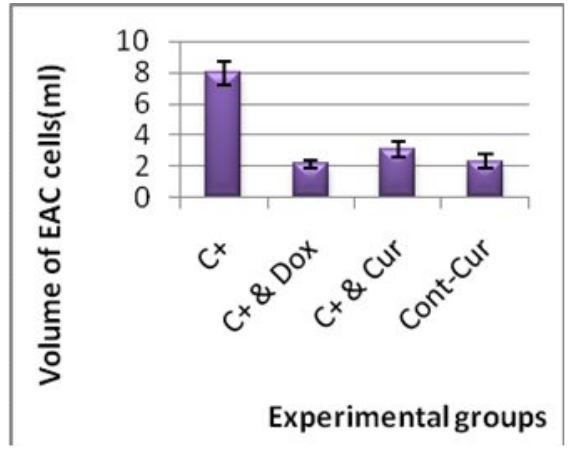

Fig. (1a): Effect of Curcumin on the volume of EAC in studied groups

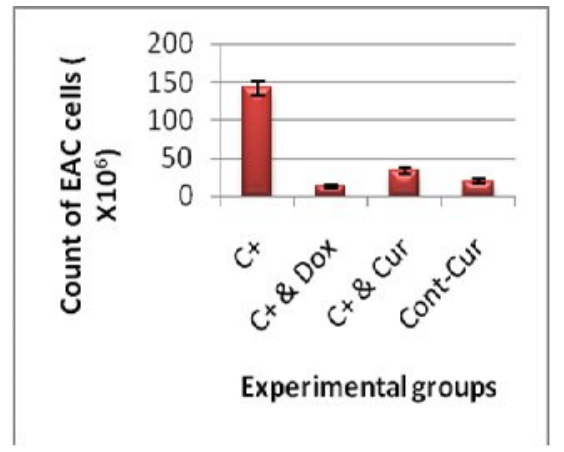

Fig. (1b): Effect of Curcumin on the count of EAC in studied groups

\section{Effect of Doxorubicin and Curcumin on NF-kB Concentration}

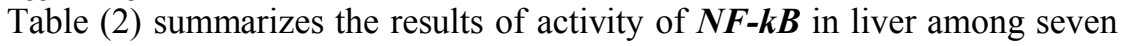
groups of animals. It was found that there was very highly significant increase in level of NF-kB in group 2 compared to group 1 [1.721 \pm 0.04483 $(\mathrm{mg} / \mathrm{ml})$ vs. $0.201 \pm 0.01792(\mathrm{mg} / \mathrm{ml})$ respectively] $(\mathrm{P}<0.001)$. Doxorubicin drug has low effect on NF_kB as it results in small decrease of NF-kB level in group 3 by $26.2 \%$ only. But Curcumin has more effect as it results in highly a significant decrease of NF-kB level in group 4 and group 5 by $33.29 \% \& 47 \%$ respectively. But the combination of curcumin with 


\section{Therapeutic Effects Of Curcumin}

Doxorubicin gives highly great results in treatment of cancer as this combination can overcome on cancer resistance asit results in highly a significant decrease of NF-kB level in group 6 and in group 7 by $76.58 \%$ $\& 80.99 \%$ respectively as represented in Fig. (2).

\begin{tabular}{|l|c|c|c|c|c|c|c|}
\hline Parameter & Group 1 & Group 2 & Group 3 & Group 4 & Group 5 & Group 6 & Group 7 \\
\hline NF_kB & & $1.721^{* * *}$ & $1.27 * * *$ & $1.148^{* * *}$ & $0.912^{* * *}$ & $0.403^{* * *}$ & $0.327^{* * *}$ \\
& $0.201 * * *$ & $\begin{array}{c}1.045 \\
\pm 0.018\end{array}$ & \pm 0.03899 & \pm 0.038 & \pm 0.0729 & \pm 0.022 & \pm 0.0302 \\
& & & & & & & \\
\hline
\end{tabular}

- $\quad * \mathrm{P}$ value $<0.05$ was considered significant. ${ }^{* *} \mathrm{P}$ value $<0.01$ was considered highly significant.

*** $\mathrm{P}$ value $<0.001$ was considered very highly significant. N.S. P value $>$ 0.05 was considered non significant.

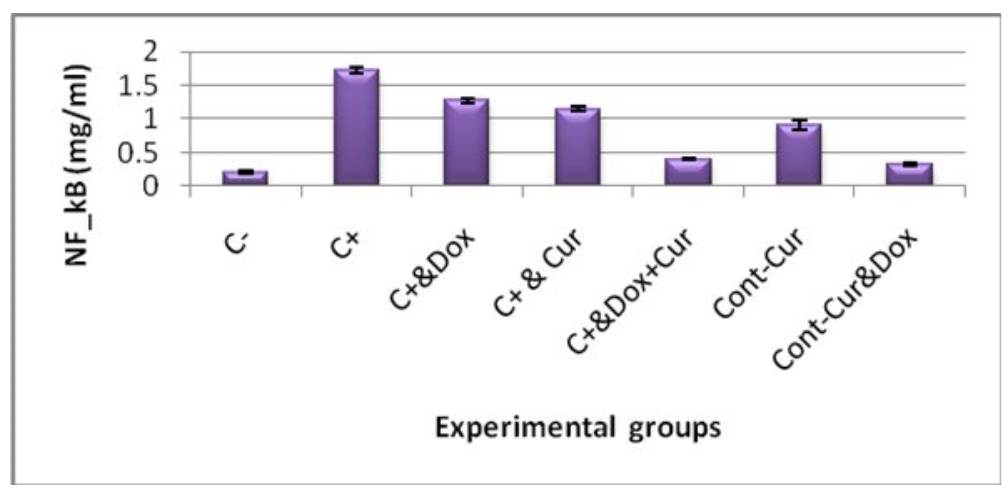

Fig. (2): Effect of Curcumin and Dox. on Concentration of NF-kB in

Studied groups

\section{Effect of Doxorubicin and Curcumin on Activity of SOD, GPX and}

\section{Catalase in liver}

Table (3) summarize the results of activity of liver SOD, GPx and Catalase among the seven groups of animals. In mice groups, there was a very highly significant decrease in SOD, GPx and Catalase levels in group II compared to group I [373.01 $\pm 9.6641(\mathrm{U} / \mathrm{gm}$ tissue) vs. $766 \pm 8.5375(\mathrm{U} / \mathrm{gm}$ tissue) and 
Faten Zahran. et al.

$530.26 \pm 42.921(\mathrm{U} / \mathrm{gm}$ tissue) vs. $2916.5 \pm 73.197(\mathrm{U} / \mathrm{gm}$ tissue); and 1.694 \pm 0.0631 vs.9.034 $\pm 0.1628(\mathrm{U} / \mathrm{gm}$ tissue) respectively] $(\mathrm{P}<0.001)$. Doxorubicin drug has been shown to exhibit antioxidant effect; as it results in highly significant increase of SOD, GPx and Catalase levels in group 3 by $67.15 \%$ ,328.07\%and 252.5\%,respectively. Also Curcumin has been shown to exhibit antioxidant activity; as it results in highly a significant increase of SOD, GPx and Catalase level in group 4 by $36.09 \%, 226.33 \% \& 139.17 \%$ respectively and in group 5 by $59.67 \%, 253.02 \% \& 193.92 \%$ respectively. But the combination of curcumin with Doxorubicin gives highly great results in treatment of cancer as this combination shows highly antioxidant activity and it results in highly a significant increase of SOD, GPx and Catalase levels in group 6 by $72.19 \%, 366.67 \% \& 366.67 \%$ respectively and in group 7 by $75.43 \%, 415.72 \% \& 374.71 \%$ respectively as represented in Fig. (3).

Table (3): Effect of Curcumin and Dox. on activity of antioxidant enzymes in the studied groups:

\begin{tabular}{|l|l|l|l|}
\hline Parameter & SOD & Catalase & GPx \\
\hline Group 1 & $766^{* * *}$ & $2916.5^{* * *}$ & $9.034^{* * *}$ \\
& \pm 8.5375 & \pm 73.197 & \pm 0.1628 \\
\hline Group 2 & $373.01^{* * *}$ & $530.26^{* * *}$ & $1.694^{* * *}$ \\
& \pm 9.6641 & \pm 42.921 & \pm 0.0631 \\
\hline Group 3 & $623.5^{* * *}$ & $2270^{* * *}$ & $5.97167 * * *$ \\
& \pm 12.341 & \pm 57.2398 & \pm 0.07167 \\
\hline Group 4 & $507.65^{* * *}$ & $1730.39 * * *$ & $4.052^{* * *}$ \\
& \pm 6.1032 & \pm 43.08099 & \pm 0.1139 \\
\hline Group5 & $595.59^{* * *}$ & $1871.9^{* * *}$ & $4.979^{* * *}$ \\
& \pm 14.25253 & \pm 48.6821 & \pm 0.07564 \\
\hline Group 6 & $642.3^{* * *}$ & $2556.89^{* * *}$ & $7.905^{* * *}$ \\
& \pm 13.7279 & \pm 33.87613 & \pm 0.09846 \\
\hline Group 7 & $654.39^{* * *}$ & $2733.07 * * *$ & $8.042^{* * *}$ \\
& \pm 11.10099 & \pm 63.3028 & \pm 0.1043285 \\
\hline
\end{tabular}

- $* \mathrm{P}$ value $<0.05$ was considered significant. ** $\mathrm{P}$ value $<0.01$ was considered highly significant.

*** $\mathrm{P}$ value $<0.001$ was considered very highly significant. N.S. P value $>$ 0.05 was considered non significant 


\section{Therapeutic Effects Of Curcumin}

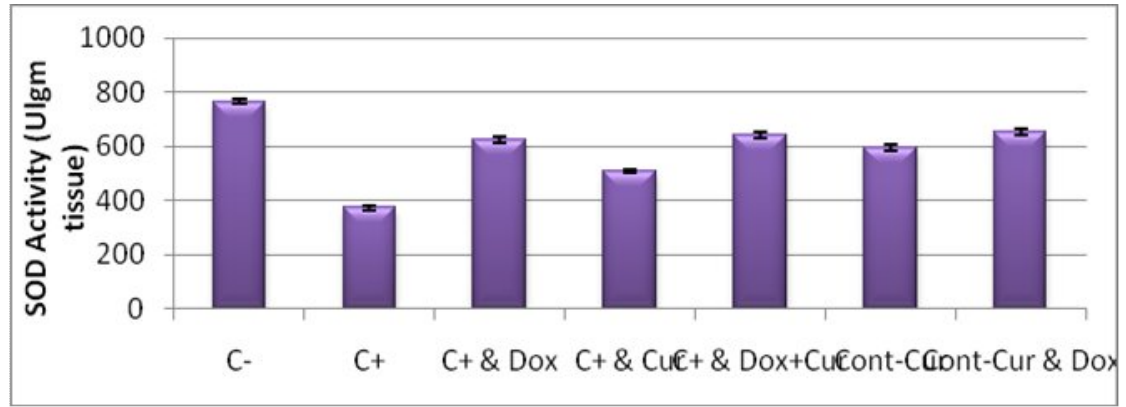

Fig. (3 a ): Effect of Curcumin and Dox. On SOD activity in Studied groups

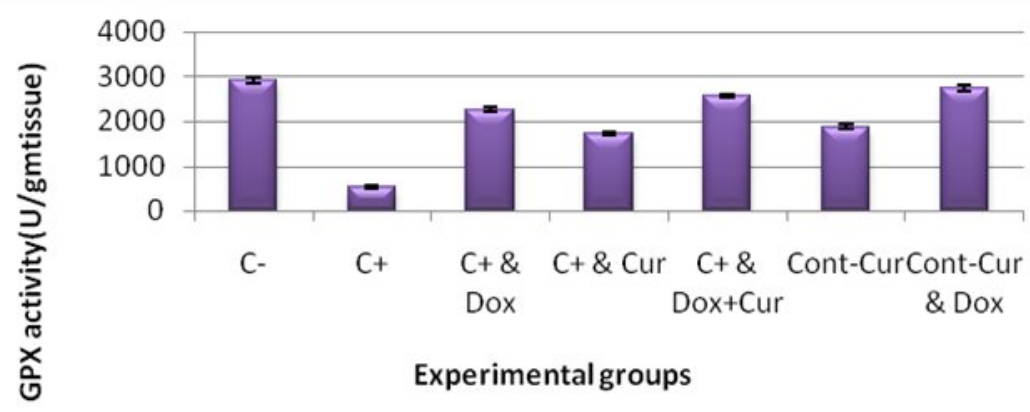

Fig. (3 b ): Effect of Curcumin and Dox. On GPx activity in Studied groups

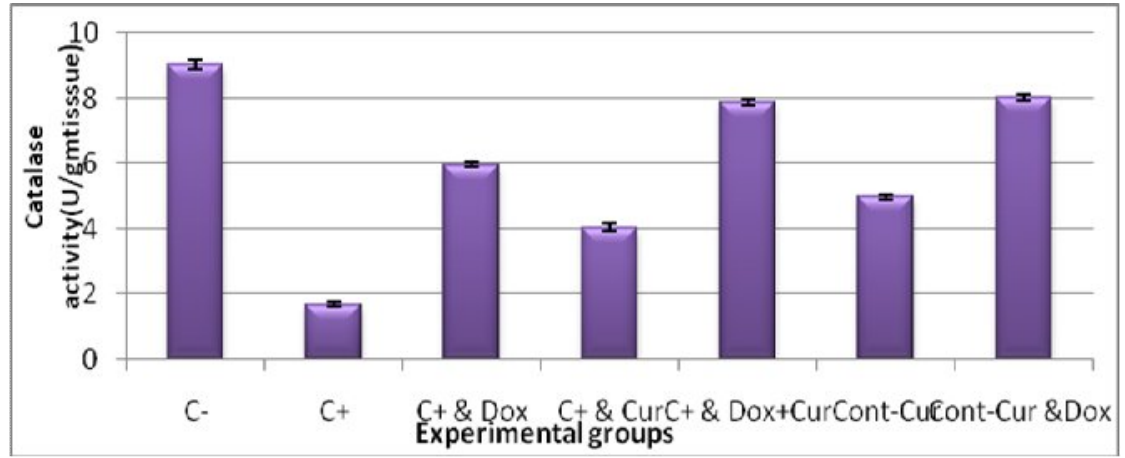

Fig. (3 c ): Effect of Curcumin and Dox. On Catalase activity in Studied groups 
Faten Zahran. et al.

\section{Effect of Doxorubicin and Curcumin on Activity of liver enzymes}

It was found that in group 2, there was a very highly increase in concentration of liver enzymes (AlT\&AST) compared to group 1 [143.2 $\pm 7.46548(\mathrm{U} / \mathrm{ml})$ vs. $9.2 \pm 2.97396(\mathrm{U} / \mathrm{ml})$, and $165 . \pm 6.65415(\mathrm{U} / \mathrm{ml})$ vs. 10.6 $\pm 2.06559(\mathrm{U} / \mathrm{ml})$ respectively] $(\mathrm{P}<0.001)$. using of Doxorubicin drug lead to damage of liver; as it results in a very highly increase of ALT \& AST level in group 3compared to group $1[161.167 \pm 7.70498(\mathrm{U} / \mathrm{ml})$ vs. 9.2 $\pm 2.97396(\mathrm{U} / \mathrm{ml})$, and172.3 $\pm 6.40833(\mathrm{U} / \mathrm{ml})$ vs. $10.6 \pm 2.06559(\mathrm{U} / \mathrm{ml})$ respectively] $(\mathrm{P}<0.001)$.. But Curcumin has been shown to improve liver state; as it results in a highly significant decrease of ALT \&AST level in group 4 by $75.62 \% \& 80.06 \%$ respectively and in group 5 by $82.82 \% \& 86.35 \%$ respectively. But the combination of curcumin with Doxorubicin gives highly great results of liver enzymes like negative control group, as this combination results in highly significant decrease of ALT \& AST level in group 6 by $91.13 \% \& 91.6 \%$ respectivelyand in group 7 by $91.15 \% \& 93.71 \%$ respectively as represented in table( 4 ) and figure (4).

Table (4): Effect of Curcumin and Dox. on activity of liver enzymes in the studied groups:

\begin{tabular}{|l|l|l|}
\hline Parameter & ALT & AST \\
\hline Group 1 & $9.2^{* * * \pm 2.97396}$ & $10.6^{* * * \pm 2.06559}$ \\
\hline Group 2 & $143.2^{* * * \pm 7.46548}$ & $165.5^{* * * \pm 6.65415}$ \\
\hline Group 3 & $161.167 * * * \pm 7.70498$ & $172.3^{* * *} \pm 6.40833$ \\
\hline Group 4 & $34.9^{* * * \pm 6.48845}$ & $33^{* * * \pm 4.16333}$ \\
\hline Group5 & $24.6^{* * *} \pm 5.54176$ & $22.6^{* * * \pm} \pm 3.71782$ \\
\hline Group 6 & $12.7^{* * * \pm 1.33749}$ & $13.9^{* * * \pm 1.19722}$ \\
\hline Group 7 & $12.1^{* * * \pm 1.72884}$ & $10.4^{* * * \pm 1.83787}$ \\
\hline
\end{tabular}

- *P value $<0.05$ was considered significant. $* * \mathrm{P}$ value $<0.01$ was considered highly significant.

*** $\mathrm{P}$ value $<0.001$ was considered very highly significant. N.S. P value $>$ 0.05 was considered non significant 


\section{Therapeutic Effects Of Curcumin}

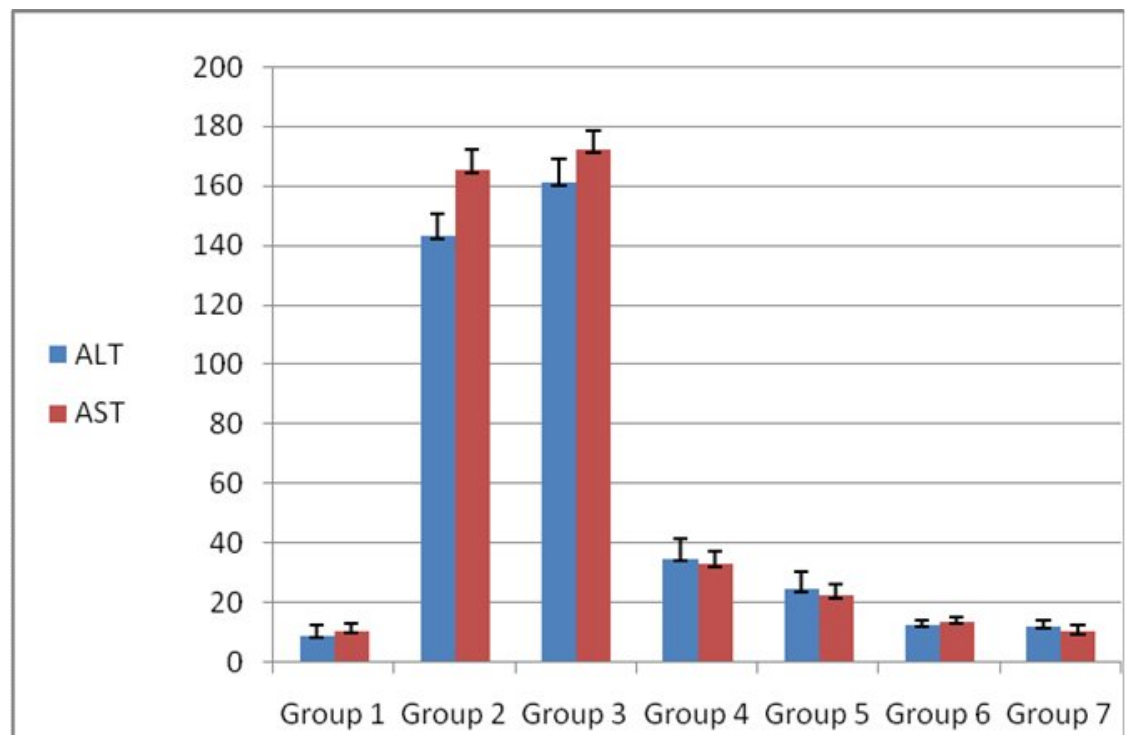

Fig. (4 ): Effect of Curcumin and Dox. On liver enzymes in Studied groups

\section{Effect of Doxorubicin and Curcumin on kidney function}

It was found that in group 2 , there was a very highly increase in concentration of creatinine\& urea compared to group $1[6.22 \pm 0.2718$ $(\mathrm{mg} / \mathrm{dL})$ vs. $0.512 \pm 0.04756(\mathrm{mg} / \mathrm{dL})$, and $120.77 \pm 6.45016(\mathrm{mg} / \mathrm{dL})$ vs. $17.42 \pm 2.16169(\mathrm{mg} / \mathrm{dL})$ respectively] $(\mathrm{P}<0.001)$.the using of Doxorubicin drug results in a very highly increase of concentration of creatinine\& urea in group 3compared to group $1[5.748 \pm 0.25879(\mathrm{mg} / \mathrm{dL})$ vs. 0.512 $\pm 0.04756(\mathrm{mg} / \mathrm{dL})$, and101.88 $\pm 5.91622(\mathrm{mg} / \mathrm{dL})$ vs. $17.42 \pm$ $2.16169(\mathrm{mg} / \mathrm{dL})$ respectively] $(\mathrm{P}<0.001)$.. But Curcumin has not any adverse effect on kidney as it results in a highly significant decrease concentration of creatinine \& urea in group 4 by $87.33 \% \& 67 \%$ respectively and in group 5 by $90.15 \% \& 74.48 \%$ respectively. But the combination of curcumin with Doxorubicin gives highly great results like negative control group, as this combination results in highly a significant decrease in concentration of creatinine $\&$ urea in group 6 by $91.26 \% \& 83.37 \%$ respectivelyand in group 7 by $91.39 \% \& 84.33 \%$ respectively as represented in table (5). 
Faten Zahran. et al.

Table (4): Effect of Curcumin and Dox. on activity of liver enzymes in the studied groups:

\begin{tabular}{|l|l|l|}
\hline Parameter & Creatinine & Urea \\
\hline Group 1 & $0.512 * * * \pm 0.04756$ & $17.42 * * * \pm 2.16169$ \\
\hline Group 2 & $6.22 * * * \pm 0.2718$ & $120.77 * * * \pm 6.45016$ \\
\hline Group 3 & $5.748 * * * \pm 0.25879$ & $101.88^{* * *} \pm 5.91622$ \\
\hline Group 4 & $0.788^{* * *} \pm 0.088794$ & $39.85^{* * * \pm 4.28518}$ \\
\hline Group5 & $0.613 * * * \pm 0.048086$ & $30.81 * * * \pm 4.01039$ \\
\hline Group 6 & $0.544 * * * \pm 0.049486$ & $20.08^{* * * \pm \pm 1.75106}$ \\
\hline Group 7 & $0.535^{* * * \pm 0.052334}$ & $18.92 * * * \pm 3.21414$ \\
\hline
\end{tabular}

- $* \mathrm{P}$ value $<0.05$ was considered significant. $* * \mathrm{P}$ value $<0.01$ was considered highly significant.

*** $\mathrm{P}$ value $<0.001$ was considered very highly significant. N.S. P value $>$ 0.05 was considered non significant.

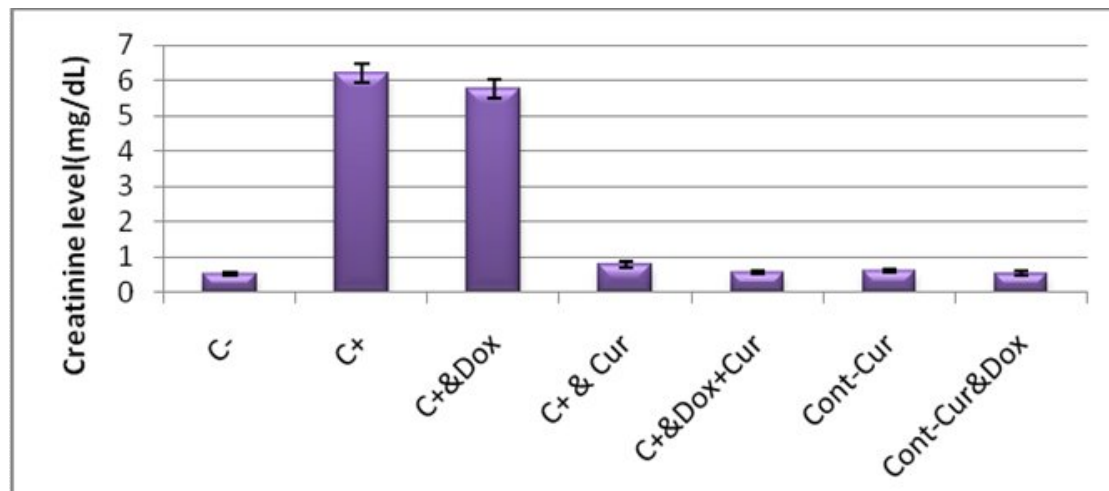

Experimental groups

Fig. (5a ): Effect of Curcumin and Dox.Level of creatinine in Studied groups 


\section{Therapeutic Effects Of Curcumin}

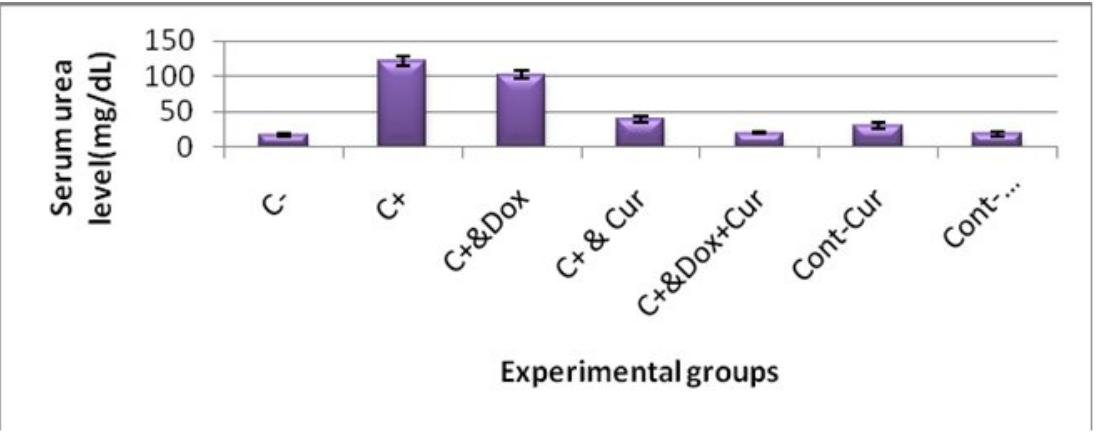

Fig. (5b): Effect of Curcumin and Dox.Level of urea in mice groups

\section{Cytological Studies of EAC in different groups:}

Cytological studies using Giemsa staining methods revealed that, Curcumin induces a significant decrease in mitotic cells in EAC compared to the increase in number of mitotic cells in positive control. The number of apoptotic cells was high in the groups treated with Curcumin "preventive and therapeutic groups"; as illustrated in Fig (5 a, b, and c), respectively. Also Doxorubicin induces a significant decrease in mitotic cells in EAC more than Curcumin, compared to the increase in number of mitotic cells in positive control.As illustrated in Fig (6 a, b, c and d), respectively. While in both groups $6 \& 7$ the combination treatment results in completely disappearance of EAC cells(Tumor cells).

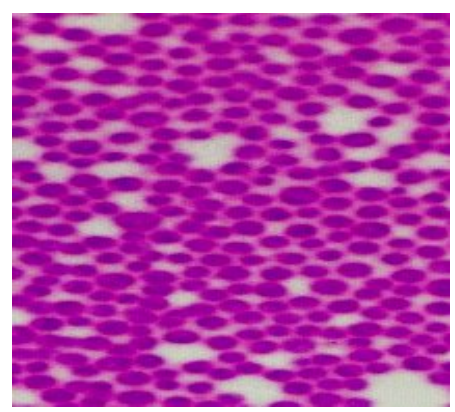

Fig.(6a):photomicrographs of EAC cells of positive control group

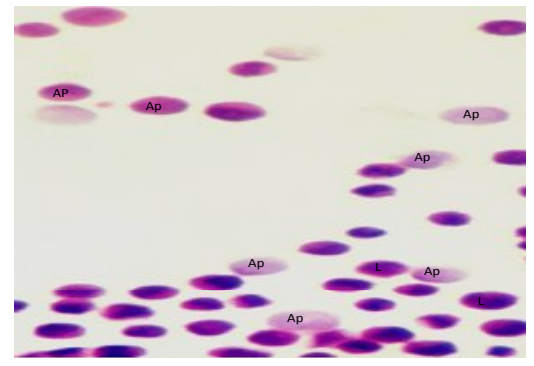

Fig.(6b):Photomicrographs of EAC cells of Therapeutic group $(\mathrm{L}=$ life cell; Ap=Apoptotic cell) 
Faten Zahran. et al.
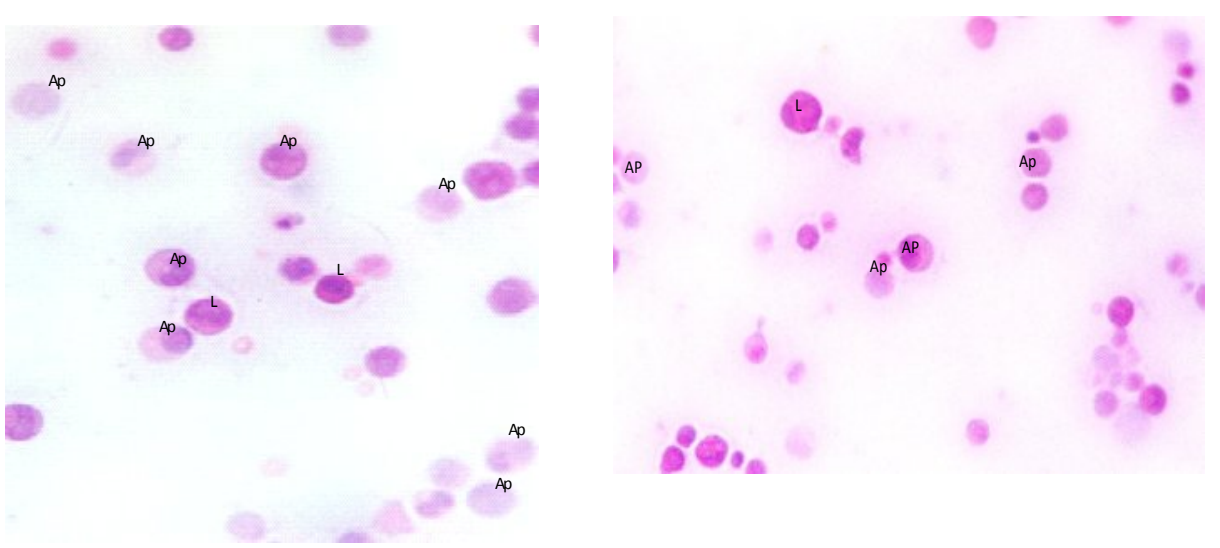

Fig.(6c): Photomicrographs of EAC cells of Preventive group (group 5). $(\mathrm{L}=$ life cell; $\mathbf{A p}=$ Apoptotic cell)

): Figfig.(6d): Photomicrographs of EAC

f doxorubicin treated group( group 3)

\section{Histopathological Studies of liver in different groups:}

Histopathological Studies using hematoxylin and eosin (H \& E) solution revealed that negative control mice liver showing normal blood vessel and normal nucleus and hepatocytes are radiating outward from a central vein in the center as presented in Fig. (7a). Positive control mice liver showing cellular inflammatory infiltration, congestion in blood vessels, hyperchromatinea, nuclear hypertrophy, debris in the central vein, hemorrhage and wide sinusoids as presented in Fig. (7b). Interestingly, treatment with doxorubicin results in most of the cellular inflammatory infiltration, congestion in blood vessels, hyperchromatinea, nuclear hypertrophy, debris in the central vein ,hemorrhage and wide sinusoids as presented in Fig. (7c).interestingly, treatment with curcumin reduced most of the pathological alterations induced by EAC cells in mice. As for the therapeutic mice group liver shows enhancement in the histology of the liver the cytoplasmic degeneration have been reduced, mild cellular inflammatory infiltration and the nuclei of hepatic cells are better as shown in Fig. (7d). While for preventive mice group, as a whole, the liver tissue showed a normal appearance to a large extent as reflected by normal array of the 


\section{Therapeutic Effects Of Curcumin}

hepatic cords radiating from the central vein, there is no appearance of cellular inflammatory infiltration, the cytoplasm is intact with normal eosinophelia and the nuclei is similar to control ones with usual chromatinophelia as shown in Fig. (7e). Moreover, treatment with combination of doxorubicin with curcumin completely reduced most of the pathological alterations induced by EAC cells in mice as livers of both group 6 \& group 7 are showingnormal blood vessel and normal nucleus and hepatocytes are radiating outward from a central vein in the center as presented in Fig. (7f \& $7 \mathrm{~g})$

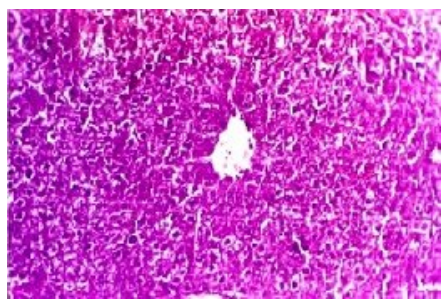

Figure (7a) Negative control group: Normal blood vessel and normal nucleus and hepatocytes are radiating outward from a central vein in the center, Hx\& E X 200

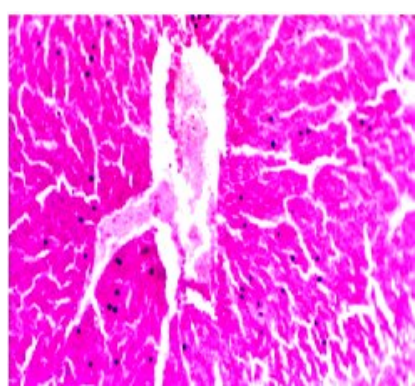

Figure (7c) doxorubicin treated group (group 3): Cellular inflammatory infiltration, congestion in blood vessels, hyperchromatinea, and nuclear hypertrophy, debris in the central vein,

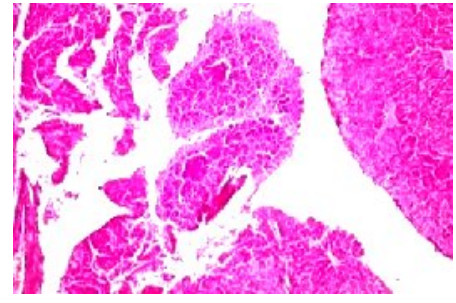

Figure (7b) Positive control group: Cellular inflammatory infiltration, congestion in blood vessels, hyperchromatinea, and nuclear hypertrophy, debris in the central vein, haemorrhage and wide sinusoids. Hx\& E X 200.

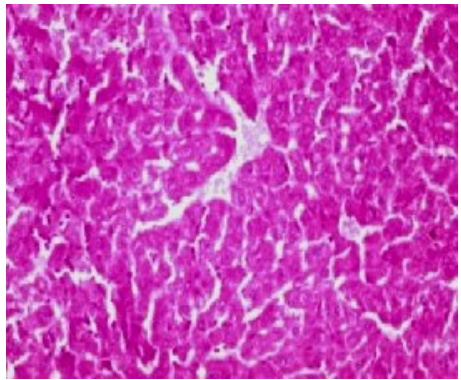

Figure (7d): Therapeutic group (group 4): Cytoplasmic degeneration have been reduced, mild cellular inflammatory infiltration and the nuclei of hepatic cells are better, Hx\& E X 200. 
Faten Zahran. et al.

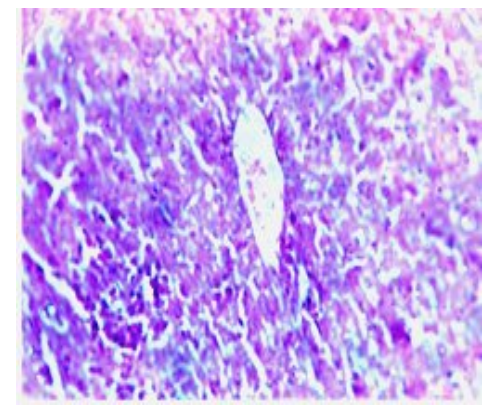

Figure (7e): Preventive group (group 5): Normal array of the hepatic cords radiating from the central vein, there isno appearance of cellular inflammatory infiltration ,the cytoplasm isintact with normal eosinophelia and the nuclei is similar to control ones with usual chromatinophelia, Hx\& E X 200

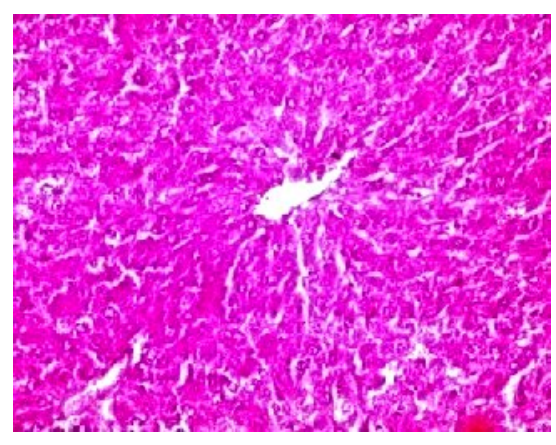

Figure $(7 \mathrm{~g})$ preventive combination group (group 7): Normal blood vessel and normal nucleus and hepatocytes are radiating outward from a central vein in the center, Hx\& E X 200.

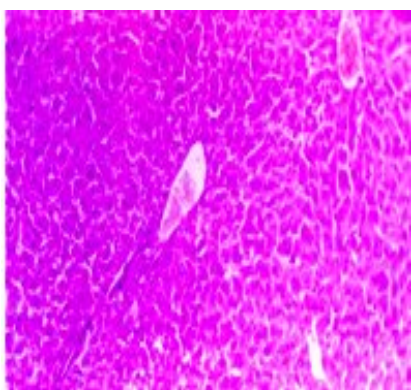

Figure (7f) treated combination group (group 6): Nearly normal blood vessel and normal nucleus and hepatocytes are radiating outward from a central vein in the center, Hx\& E X 200. 


\section{Therapeutic Effects Of Curcumin}

\section{DISCUSSION}

Cancer, a group of diseases characterized by uncontrolled growth and spread of abnormal cells, is a major public health problem in the United States and many other parts of the world ${ }^{(\mathbf{3 3 )} \text {. }}$ It is, therefore, essential that new therapeutic options are needed for cancer therapy with attention to toxicity and side effects, besides the major treatment modalities including surgery, immunotherapy and radiotherapy ${ }^{(34)}$. Drug resistance is a major cause of relapse and the incurability of cancer. The management of cancer involves procedures, which include surgery, radiotherapy, and chemotherapy. Development of chemo-resistance is a persistent problem during the treatment of local and disseminated disease .An accumulating body of evidence suggests that constitutive activation of the NF_kB pathway can contribute to cancer development, progression and resistance to cancer therapy ${ }^{(35)}$.Therefore, inhibition of the NF_kB defense pathway has the potential to increase the therapeutic index of doxorubicin. In this regard NF_kB inhibitors may emerge as the most promising anti-tumor agents and novel tumor sensitizers for doxorubicin ${ }^{(25)}$. It is well known that the systemic availability of Curcumin is very low after oral administration, because most of Curcumin is metabolized in the intestine ${ }^{(36)}$. Bioperine is a pepper extract that increases the absorption of nutrient supplements. The medicinal properties of curcumin obtained from Curcuma longaL. cannot be utilized because of poor bioavailability due to its rapid metabolism in the liver and intestinal wall. In this study, the effect of combining piperine, a known inhibitor of hepatic and intestinal glucuronidation, was evaluated on the bioavailability of curcumin. Thus Bioperine is co-administrated with curcumin in order to increase its bioavailability ${ }^{(37)}$. So Curcumin powder $(400 \mathrm{mg} / \mathrm{Kg})$ is dissolved in saline and give orally to mice by gavage tube. Our results revealed that, doxorubicin decrease the volume of EAC significantly in doxorubicin-treated group (group 3) by $73.2 \%$, Also, it reduces the count of EAC cells significantly in this group by $90.67 \%$, and inhibit NF_kB by $26.2 \%$ compared to positive control group (bearing EAC), .While the treatment with curcumin results in decrease the volume of EAC significantly in the therapeutic(group 4) and preventive group (group 5) by $61.5 \%$ and $70.94 \%$, respectively. Also, it reduces the count of EAC cells significantly in both groups by $76.42 \%$ and $86.43 \%$, respectively, and inhibits NF_kB in both groups by $33.29 \%$ and $47 \%$,respectively, compared to positive control group (bearing EAC). But the combinational therapy of doxorubicin with curcumin results in completely disappearance of EAC cells 
(tumor cells) in group $6 \&$ group 7, also this combined therapy results in inhibition of NF_kB in both groups by $76.58 \%$ and $80.99 \%$,respectively, compared to positive control group (bearing EAC). The anti-tumor effect of Curcumin has been attributed in part to the suppression of cell proliferation, reduction of tumor load and induction of apoptosis in various cancer models both in vitro and in vivo ${ }^{(\mathbf{3 8})}$. Curcumin may also operate through the suppression of NF-kB activation, where this factor required for the expression of genes involved in cell proliferation, cell invasion, metastasis, angiogenesis, and resistance to chemotherapy ${ }^{(39)}$. The regulatory contribution of $\mathrm{NF}_{-} \mathrm{kB}$ and $\mathrm{p} 53$ to cancer development and progression is well documented where inactivation of $\mathrm{p} 53$ and hyper-activation of NF-kB are the common occurrences ${ }^{(\mathbf{3 9})}$. Likewise there are studies reporting that NF-kB, being induced in drug-treated resistant cells, interfered with $\mathrm{p} 53$ functions by p300 sequestration. Inhibition of $\mathrm{NF}_{-} \mathrm{kB}$ by curcumin or $\mathrm{I} \kappa \mathrm{B} \alpha$ super repressor or SMAR1-shRNA rescued p300 from NF_kB/clutch to restrain the resistance pathway. Consistently there are studies reporting that NF_kB has a high-affinity for p300 that may lead to its sequestration thereby making it unavailable to other transcription factors ${ }^{(\mathbf{4 0 )}}$. Anti-oxidant effect of Curcumin showed a very highly significant increase in SOD level by (36.09\% and 59.67\%; respectively, $\mathrm{p}<0.001$ ); and increase in catalase level by $(139.17 \%$ and $193.92 \%$; respectively, $\mathrm{p}<0.001)$ and increase in GPx level by $(226.33 \%$ and $253.02 \%$,respectively, $\mathrm{p}<0.001)$ in group 4 and group 5 compared to EAC group, While doxorubicin showed a very highly significant increase in SOD level by $(67.15 \%, \mathrm{p}<0.001)$; and increase in catalase level by $(252.5 \%, \mathrm{p}<0.001)$ and increase in GPx level by $(328.07 \%$, $\mathrm{p}<0.001)$ in group 3 compared to EAC group . On the other hand, the combinational therapy of doxorubicin with curcumin showed a very highly significant increase in SOD level by $(72.19 \%$ and $75.43 \%$; respectively, $\mathrm{p}<0.001)$; and increase in catalase level by $(366.67 \%$ and $374.71 \%$,respectively, $\mathrm{p}<0.001)$ and increase in GPx level by $(382.18 \% \%$ and $415.72 \%$, respectively, $\mathrm{p}<0.001$ ) in group 6 and group 7 compared to EAC group. Curcumin was found to be a very potent anti-oxidant. As, the phenolic (-OH) plays a major role in the anti-oxidant activity of curcumin ${ }^{(41)}$. Curcumin has also been shown to quench reactive oxygen species and scavenge superoxide anion radicals and hydroxyl radicals and strongly inhibits NO production by down-regulating inducible nitric oxide synthase gene expression ${ }^{(42)}$. Curcumin inhibit free radical generation and act as free radical scavengers and antioxidants, inhibiting lipid per-oxidation and oxidative DNA damage, with abilities to inhibit activation of $\mathrm{NF}-\mathrm{kB}^{(43)}$. As 


\section{Therapeutic Effects Of Curcumin}

Curcumin can induce apoptosis by different mechanisms, such as, by inhibiting the expression of the anti-apoptotic genes bcl-2 and bcl-xL, by inhibiting AP-1 and NF-kB transcription factors ${ }^{(44)}$. Physiologically bcl-2 protein blocks the apoptotic process by inhibiting the release of cytochrome $\mathrm{C}$ from mitochondria whereas it locates at the cytoplasmic surface of the mitochondrial membrane ${ }^{(45)}$. In fact, results of liver enzymes, kidney function tests and histopathological studies indicate that tumor itself as well as doxorubicin induced severe immunosuppression, increased liver toxicity and caused cardiovascular injury. Previous reports describing that this photochemical can protect the host immune system from the toxicity rendered by the anticancer drug in tumor-bearer. Our results showing hepatoprotective effect of curcumin were supported by the study of Chuang et $\mathrm{al}^{(46)}$. who showed that curcumin-containing diet inhibits murine hepatocarcinogenesis. Curcumin has also been shown to prevent alcoholinduced liver disease in rats by inhibiting the expression of NF-kBdependent genes $\left({ }^{47)}\right.$. At the same time curcumin inhibited endotoxin mediated activation of $\mathrm{NF} \mathrm{kB}$ and suppressed the expression of cytokines, chemokines, $\mathrm{COX}-\overline{2}$, and iNOS in Kupffer cells. Apart from immuno-toxicity and liver damage, curcumin also protected cardiac tissue from doxorubicininduced toxicity ${ }^{(\mathbf{4 8 )}}$.Cytogenetic study of EAC in mice groups indicates that, curcumin and doxorubicin induce apoptosis. Staining methods revealed a significant increase in number of mitotic cells in EAC untreated group (positive control) (Fig. 6 a). Curcumin induces significant decrease in mitotic cells in EAC (treated groups) as illustrated in Fig. (6d) and 6e).Doxorubicin induces a highly significant decrease in mitotic cells in EAC (group 3)as

illustrated in fig.(6c).But the Combinational treatment of curcumin/Doxorubicin results in completely disappearance of EAC cells (tumor cells). Holy ${ }^{(49)}$ reported disruption of mitotic spindle structure and induction of micro-nucleation in human breast cancer cells by curcumin "yellow pigment".

These observation of curcumin sensitizing doxorubicin-resistant ascites carcinoma cells, emphasizes that curcumin in combination with doxorubicin can be used as an effective treatment strategy to reverse breast cancer drug resistance. Consistently curcumin has been reported to increase the efficacy of doxorubicin by modulating the function of the multidrug resistance linked ATP-binding cassette transporter $\mathrm{ABCG} 2^{(73)}$ and to sensitize glioma cells in a p53 and caspase independent manner by inhibition of AP-1 and NF_kB signaling pathways ${ }^{(50)}$. 
Faten Zahran. et al.

This observation is in agreement with phase-I clinical data showing that curcumin is well tolerated and suggested that curcumin could be a potential therapeutic agent for combination chemotherapy with DNAdamaging agents ${ }^{(51)}$.Such differential activities of curcumin strongly support its candidature as a potential chemo sensitizing agent suggesting that a combinatorial regimen of curcumin and doxorubicin can be framed and tested for reversal of anthracycline-resistance in future human clinical trials.

\section{REFERENCES}

1. Jemal A, Murrary T, Ward E, Samuels A, Tivari RC, Ghafoor A, Feuer E and Thun MJ (2005):Cancer statistics. Cancer J. Clin 55: 1015.

2. Ferlay J, Shin HR, Bray F, et al (2010): Estimates of worldwide burden of cancer in 2008. Int J Cancer.

3. Russo J, Hu YF, Yang X, Russo IH(2000):Developmental, cellular, and molecular basis of human breast cancer. J Natl Cancer InstMonogr, $27: 17 \mathrm{e} 37$.

4. Yu B, Shen H, Gao F, Fan Y, Sun Z (2010) : Expression of the manganese superoxide dismutase in patients with breast cancer. Kaohsiung Journal of Medical Sciences 27, 167e172.

5. Chintamani, M.T., Mishra, A., Agarwal, U., and Saxena, S. (2011) :World J SurgOncol 9, 19.

6. Campbell, K.J., O'Shea, J.M., and Perkins, N.D. (2006): BMC Cancer 6, 101.

7. Jang J., Kay C., You C., Kim C., Bae S., Choi J., Yoon S., Han C., Jung H., Choi I. (2009): Simultaneous multitarget irradiation using helical tomotherapy for advanced hepatocellular carcinoma with multiple extrahepatic metastases, Int. J. Radiat. Oncol. Biol. Phys. 74: 412-418. 


\section{Therapeutic Effects Of Curcumin}

8. Kane A. and Yang I. (2010):Interferon-gamma in brain tumor immunotherapy.Neurosurg. Clin. N. Am. 21: 77-86.

9. Hong-Fang J., Xue-Juan L., Hong-Yu Z. 200 (2009): Natural products and drug discovery, EMBO Rep. 10: 194.

10. Mehmet Ozaslan,IsikDidemKaragoz, Ibrahim HalilKilic and MuhammedEminGuldur (2011): African Journal of Biotechnology 10(13), 2375-2378, 28 .

11. Klauning JE, Kamendulis LM (2004): The role of oxidative stress in carcinogenesis. Annu Rev PharmacolToxicol . 44: 239-67.

12. Durackova, Z.(2010): Some current insights into oxidative stress. Physiol. Res. 59: 459-469.

13. Rahman, I., Biswas, S. K., and Kirkham, P. A.(2006):Regulation of inflammation and redox signaling by dietary polyphenols, Biochem. Pharmacol 72, 1439-1452.

14. Ströfer, M.; Jelkmann, W.;andDepping, R. (2011):Curcumin decreases survival of Hep3B liver and MCF-7 breast cancer cells: the role of HIF. Strahlentherapie und Onkologie 187 (7): 393-400.

15. Shukla, P. K.; Khanna, V. K.; Ali, M. M.; Khan, M. Y.;andSrimal, R. C. (2008): Anti-ischemic effect and anti-inflammatory properties of curcumin in rat brain. Neurochemical Research 33 (6): 1036-1043.

16. Campbell, K.J., O'Shea, J.M., and Perkins, N.D. (2006): BMC Cancer 6, 101.

17. Arafa, el -S.A., Zhu, Q., Shah, Z.I., Wani, G., Barakat, B.M., Racoma, I., El-Mahdy, M.A., and Wani, A.A. (2011):Mutat Res 706, 28-35.3

18. 18-Liu, X., Wang, B., Ma, X., and Guo, Y. (2009): Jpn J ClinOncol 39, 418-424.

19. Perkins ND. (2007):Integrating cell-signaling pathways with $\mathrm{NF \kappa B}$ and IKK function. Nature Rev Mol Cell Biol 8: 40-62. 
Faten Zahran. et al.

20. Panicker SR,andKartha CC.(2010):Curcumin attenuates glucose-induced monocyte chemoattractant protein-1 synthesis in aortic endothelial cells by modulating the nuclear-factor kappaB pathway. Pharmacology 85:18-26.

21. Suaib Luqman1, and John M. Pezzuto (2010):NFkB: A Promising Target for Natural Products in Cancer Chemoprevention, Phytother. Res. 24: 949-963.

22. McLiman, W.F, Dairs E.V., Glover F.L., and Rake G.W. (1957). the submerged culture of mammalian cells. The Spinner Culture. J. Immunol.; 79:428,

23. Nishikimi,M.,Roa,N.A.,andYogi,K.(1972):Biochem.Bioph.Res.Common., 46,849-854.

24. Aebi H (1984):Catalase in vitro. Method Enzymol. 105: 121-126.

25. D.E.Paglia and W.N.Valentine (1967):lab.clin.Med.70:158-169.

26. Reitman, A. and Frankel, S., (1957):Amer J.Clin.Path.,28:56.

27. Bartles H., Bohmer M., Heirli C. ( 1972) :Clin ,Chem, Acta 37,193.

28. Fawcett, J.K and Soctt, J.E. (1960):J, Clin., Path.13:156-159.

29. Adams,J.(2001):proteasome inhibition in cancer,development of P5-341.semin.oncol.28(6):613-619.

30. Amr Y E,(1986): Studies on the effect of Dietary Magnesium and manganese on Experimental Tumor Cell (in mice). Thesis, AinShamsUniversity, p.35.

31. Culling C F A (1983):Handbook of histopathological and histochemical technique, 3rd edition .Butter Worth London ,Boston: 214.

32. Levesque, R. (2007): SPSS., Programming and Data Management: A Guide for SPSS and SAS Users, Fourth Edition, SPSS Inc., Chicago Ill. 


\section{Therapeutic Effects Of Curcumin}

33. Pezzuto JM, Kosmeder JW, Park EJ et al.( 2005):Characterization of natural product as chemopreventive agents. In Cancer Chemoprevention, Kelloff GJ, Hawk ET, Sigman CC (eds). Humana Press Inc.: Totowa, NJ; 2: 3-37.

34. Jang JW, Kay CS, You CR, Kim CW and Bae SH (2009):.Simultaneous multitarget irradiation using helical tomotherapy for advanced hepatocellular carcinoma with multiple extrahepatic metastases. Int. J. Radiat. Oncol. Biol. Phys. 74: 412-418.

35. Liu, X., Wang, B., Ma, X., and Guo, Y. (2009) :Jpn J ClinOncol 39, 418424.

36. Ireson, C.R., Jones, D.J.L., Orr, S., Coughtrie, M.W.H., Boocock, D.,Williams, M.L., Farmer, P.B., Steward, W.P., Gescher, A.J.(2002).: Metabolism of the cancer chemopreventive agent curcumin in human and rat intestine. Cancer Epidemiol Biomarkers Prev. 11: $97-$ 104

37. Joshua D. Lambert, Jungil Hong, Dou Hwan Kim, Vladimir M. Mishin, and Chung S. Yang J.(2004): Nutr. 134: 1948-1952.

38. Dhillon N., Aggarwal B.B., Newman R.A., Wolff R.A., Kunnumakkara A.B., Abbruzzese J.L., Ng C.S., Badmaev V., Kurzrock R.(2008)::Phase II trial of curcumin in patients with advanced pancreatic cancer. Clin Cancer Res, 14:4491-4499.

39. Baldwin, A.S.(2001): Control of oncogenesis and cancer therapy resistance by the transcription factor NF-kappaB. J Clin Invest. 107(3), 241-246.

40. Wang, Q.E., Milum, K., Han, C., Huang, Y.W., Wani, G., Thomale, J., and Wani, A.A. (2011):Mol. Cancer 10.

41. Furia, B., Deng, L., Wu, K., Baylor, S., Kehn, K., Li, H., Donnelly, R., Coleman, T., and Kashanchi, F. (2002):J BiolChem 277, 4973-4980.

42. Yang S.S., Huang C.C., Chen J.R., Chiu C.L., Shieh M.J., Lin S.J., Yang S.C.(2005):Effects of ethanol on antioxidant capacity in isolated rat hepatocytes. World J Gastroenterol; 11: 7272-7276. 
43. Gaurisankar S., and Tanya D.(2008):Anti cancer effects of curcumin: cycle of life and death. Cell Division. 3:14.

44. Eun M.J., Jun H.L., Tae J.L., Jong W.P., Kyeong S.C. and Taeg K.K.(2005):Curcumin sensitizes tumor necrosis factor-related apoptosisinducing ligand (TRAIL)-induced apoptosis through reactive oxygen species-mediated up-regulation of death receptor 5 (DR5). Carcinogenesis. 26 (11); pp.1905-1913.

45. Jutooru I., Chadalapaka G., Lei P., Safe S.(2010):Inhibition of NF кB and pancreatic cancer cell and tumor growth by curcumin is dependent on specifi city protein down-regulation. J Biol Chem. 285: 25332-25344.

46. Osman H.G., Gabr O.M., Lotfy S., and Gabr S.(2007):serum levels of Bcl-2 and cellular oxidative stress in patients with viral hepatitis. Indian Journal of Medical Microbiology. 25(4):323-9.

47. Chuang, S.E., Kuo, M.L., Hsu, C.H., Chen, C.R., Lin, J.K., Lai, G.M., Hsieh, C.Y., and Cheng, A.L. (2000):Carcinogenesis 21, 331-335.

48. Nanji, A.A., Jokelainen, K., Tipoe, G.L., Rahemtulla, A., Thomas, P., Dannenberg A.J. (2003):AJ Am J PhysiolGastrointest Liver Physiol 284, G321-G327. Bioorg Med ChemLett 8, 339-344.

49. Chearwae, W., Shukla, S., Limtrakul, P., and Ambudkar, S.V. (2006): Mol Cancer Ther 5, 1995-2006.

50. Dhandapani, K.M., Mahesh, V.B., and Brann, D.W. (2007):J Neurochem 102, 522-538.

51. Cheng, A.L., Hsu, C.H., and Lin, J.K. (2001):Anticancer Res. 21, 2895 2900. 
Therapeutic Effects Of Curcumin

e 